\title{
Pinoresinol diglucoside exhibits protective effect on dexamethasone-induced osteoporosis in rats
}

\author{
Zhan-Feng Zhang, Ji-Kang Min, Dan Wang, Jian-Ming Zhong* \\ Department of Orthopaedics, The First People's Hospital of Huzhou, Huzhou 313000, Zhejiang, PR China \\ *For correspondence: Email: zhongjianminghz@sina.com
}

Received: 26 May 2016

Revised accepted: 16 October 2016

\begin{abstract}
Purpose: To investigate the effect of pinoresinol diglucoside (PDG) on dexamethasone-induced osteoporosis in rats.

Methods: Sixty Wistar rats were randomly and equally divided into normal, control, alendronate and PDG (10, 20 or $40 \mathrm{mg} / \mathrm{kg}$ ) groups. Bone tissue parameters, including length, transverse diameter, weight, bone mineral content (BMC) and bone mineral density (BMD), were determined using vernier caliper, electronic balance and single photon bone mineral density meter. Serum biochemical indices, including $\mathrm{Ca}^{2+}$, inorganic phosphorus (IP), IL-6, TNF- $\alpha$ and alkaline phosphatase (ALP), were determined using colorimetry and enzyme-linked immunosorbent assay (ELISA). Osteoprotegerin (OPG) and receptor activator of nuclear factor-KB ligand (RANKL) proteins were detected by Western blot.

Results: PDG (10, 20 or $40 \mathrm{mg} / \mathrm{kg})$ increased significantly $(p<0.05$ or 0.01$)$ transverse diameter (3.64 - 3.79 vs. $3.31 \mathrm{~mm})$, weight $(0.73-0.78$ vs. $0.67 \mathrm{~g})$, BMC $(0.16-0.23$ vs. $0.12 \mathrm{~g} / \mathrm{cm}), B M D(0.27-$ 0.35 vs. $\left.0.22 \mathrm{~g} / \mathrm{cm}^{2}\right)$ of right femur, serum $\mathrm{Ca}^{2+}$ level $(2.16-2.39 \mathrm{vs} .1 .94 \mathrm{mmol} / \mathrm{L})$, and OPG level of left femur, compared with those in the control group. PDG (10, 20 or $40 \mathrm{mg} / \mathrm{kg})$ reduced significantly (p $<0.05$ or 0.01$)$ serum IP (1.34 - 1.14 vs. $1.76 \mathrm{mmol} / \mathrm{L}), \mathrm{IL}-6$ (103.25 - $95.38 \mathrm{vs} .108 .74 \mathrm{ng} / \mathrm{L}), \mathrm{TNF}-\alpha$ (87.46 - 82.05 vs. 92.38 ng/L), ALP (334.79 - 276.32 vs. 486.45 U/L) levels or activities, and RANKL level of left femur, compared with those in the control group.

Conclusion: PDG exhibits a protective effect on dexamethasone-induced osteoporosis by increasing bone mass and regulating bone metabolism. Thus, PDG may be a candidate drug for treating osteoporosis.
\end{abstract}

Keywords: Pinoresinol diglucoside, Osteoporosis, Bone mass, Bone metabolism, Dexamethasone, Osteoprotegerin

Tropical Journal of Pharmaceutical Research is indexed by Science Citation Index (SciSearch), Scopus, International Pharmaceutical Abstract, Chemical Abstracts, Embase, Index Copernicus, EBSCO, African Index Medicus, JournalSeek, Journal Citation Reports/Science Edition, Directory of Open Access Journals (DOAJ), African Journal Online, Bioline International, Open-J-Gate and Pharmacy Abstracts

\section{INTRODUCTION}

Osteoporosis (OP) is a systemic disease of skeleton characterized by reduction of bone mass and disruption of bone architecture, resulting in reduced bone strength and increased risk of fragility fractures which represent the key clinical symptom of OP [1,2]. Based on etiology, OP is divided into 3 types: primary, secondary and idiopathic OP. Secondary OP is induced by some drugs and diseases, such as glucocorticoids and lupus erythematosus $[3,4]$.

Glucocorticoids, a class of steroid hormones, are secreted by zona fasciculate of adrenal cortex. Physiological doses of glucocorticoids can regulate biosynthesis and metabolism of sugar, fat and protein [5]. Supra-physiological doses of 
glucocorticoids exhibit anti-immune, anti-shock and anti-inflammatory activities, and therefore, glucocorticoids are widely used to treat anaphylactic disease, inflammation, severe infection, etc [6]. However, long-term excessive use of glucocorticoids will induce bone disruption, especially OP. Nowadays, glucocorticoids-induced OP is the most common secondary OP [7].

At present, it is the research focus to find safe and effective drugs for preventing and treating glucocorticoids-induced OP. Du-Zhong (Eucommia ulmoides Oliv.) can be used to prevent ovariectomy-induced $\mathrm{OP}$ in rats and disuse-induced OP in hind limb suspension rats $[8,9]$. Pinoresinol diglucoside (PDG, Figure 1) is a main constituent of Du-Zhong [10], but its effect on OP remains unknown. Therefore, this work was designed to investigate the effect of PDG on dexamethasone (DEX, a kind of glucocorticoid)induced OP in rats.<smiles>COc1cc([C@@H]2OC[C@@H]3[C@@H](c4ccc(O[C@@H]5OC(CO)[C@H](O)[C@H](O)[C@H]5O)c(OC)c4)OC[C@H]23)ccc1OC1O[C@H](CO)[C@@H](O)[C@H](O)C1O</smiles>

Figure 1: Chemical structure of pinoresinol diglucoside (PDG)

\section{EXPERIMENTAL}

\section{Chemicals and reagents}

DEX injection was provided by Henan Runhong Pharmaceutical Co., Ltd. (Zhengzhou, China). Alendronate was purchased from Wante Pharmaceutical Co., Ltd. (Haikou, China). PDG (purity $\geq 98 \%$ ) was purchased from SigmaAldrich (Shanghai, China). $\mathrm{Ca}^{2+}$, inorganic phosphorus (IP) and alkaline phosphatase (ALP) assay kits were purchased from Nanjing Jiancheng Bioengineering Institue (Nanjing, China). IL-6 and TNF- $\alpha$ ELISA kits were obtained from Neobioscience (Shanghai, China). Enhanced BCA protein assay kit was purchased from Beyotime (Haimen, China). Primary antibodies for $\beta$-actin, osteoprotegerin (OPG) and receptor activator of nuclear factor-kB ligand (RANKL), along with horse radish peroxidase (HRP)-conjugated anti-rabbit antibody were purchased from Cell Signaling Technology (Beverly, MA, USA) and Abcam (Cambridge,
UK). Enhanced chemiluminescence detection kit for HRP was provided by Biological Industries (Kibbutz Beit Haemek, Israel).

\section{Animals}

Wistar female rats $(180 \pm 20 \mathrm{~g})$ were provided by Laboratory Animal Centre, Huzhou Institute for Food and Drug Control and were housed in a temperature controlled vivarium $\left(25^{\circ} \mathrm{C}\right)$ with relative humidity of $65 \%$ and 12/12-h light-dark cycle. All rats have free access to water and food. All animal treatments were conducted in strict accordance with the National Institutes of Health Guide for Care and Use of Laboratory Animals [11]. This study was performed with the approval of the ethics committee of Laboratory Animal Centre, Huzhou Institute for Food and Drug Control (protocol no. HZIFDC LACEC 2014035).

\section{Animal experiments}

Sixty Wistar rats were randomly and averagely divided into normal, control, alendronate and PDG (10, 20 or $40 \mathrm{mg} / \mathrm{kg}$ ) groups. After fasting for $12 \mathrm{~h}$, rats in the control, alendronate or PDG $(10,20$ or $40 \mathrm{mg} / \mathrm{kg})$ groups were administrated orally with normal saline, $1 \mathrm{mg} / \mathrm{kg}$ alendronate, $10 \mathrm{mg} / \mathrm{kg}$ PDG, $20 \mathrm{mg} / \mathrm{kg}$ PDG or $40 \mathrm{mg} / \mathrm{kg}$ PDG at 9:00 a.m. once a day for 8 weeks, respectively and injected intramuscularly with $2.5 \mathrm{mg} / \mathrm{kg}$ DEX at 6:00 p.m. twice a week for 8 weeks to establish OP model. Rats in the normal group were administrated orally with normal saline at 9:00 a.m. once a day for 8 weeks and injected intramuscularly with normal saline at 6:00 p.m. twice a week for 8 weeks. Different amounts of alendronate or PDG were dissolved in normal saline to get different concentrations such that each rat received an intragastric volume of 20 $\mathrm{mL} / \mathrm{kg}$. Body weight of rats in all groups was weighed using electronic balance once a week for 8 weeks.

After being deeply narcotized with $10 \%$ chloral hydrate at a dose of $3.0 \mathrm{~mL} / \mathrm{kg}$ by intraperitoneal injection on 57th day, the abdominal aortic blood of each rat was collected and centrifuged at 3000 rpm for $10 \mathrm{~min}$ at $4{ }^{\circ} \mathrm{C}$ to obtain serum, which was stored at $-20{ }^{\circ} \mathrm{C}$ for further analysis. Then the left and right femurs of each rat were rapidly separated and were flushed with normal saline to remove residual blood. All clean femurs were stored at $-80{ }^{\circ} \mathrm{C}$ for further analysis.

\section{Determination of bone tissue parameters}

Length and transverse diameter of right femur were measured by vernier caliper. Weight of right 
femur was weighed using electronic balance. Bone mineral content (BMC) and bone mineral density (BMD) of right femur were determined using a BH41-HH6005 single photon bone mineral density meter (Beijing Zhongxi Yuanda Science and Technology Co., Ltd., China).

\section{Determination of serum biochemical indices}

Serum $\mathrm{Ca}^{2+}, \mathrm{IP}, \mathrm{IL}-6, \mathrm{TNF}-\mathrm{\alpha}$ and ALP levels or activities were determined using corresponding kits according to the manufactures' instruction for each. After reactions were completed, absorbance of each index in each sample was determined using a Thermo Scientific Microplate Reader (Waltham, MA, USA). The absorbance for each index was used to calculate the activity or level based on the corresponding standard curves.

\section{Detection of OPG and RANKL proteins}

OPG and RANKL levels in left femur were detected by Western blot. After pretreatment with lysis buffer, grinding and centrifugation at 12000 rpm for $10 \mathrm{~min}$ at $4^{\circ} \mathrm{C}$, total protein of left femur tissue was extracted, and its concentration was determined using enhanced BCA protein assay kit. Then equal amounts of total protein (about 40 $\mu \mathrm{g}$ ) were separated by $10 \%$ sodium dodecyl sulfate/polyacrylamide and blotted on PVDF membrane. After blocking with $5 \%$ non-fat milk, PVDF membranes were incubated with primary antibodies for $\beta$-actin, OPG and RANKL overnight at $4{ }^{\circ} \mathrm{C}$. After washing with Tris buffered saline-Tween (TBS-T), PVDF membranes were incubated with HRPconjugated anti-rabbit antibody in TBS-T at room temperature for $2 \mathrm{~h}$. Then, the PVDF membranes were washed with TBS-T, and proteins were detected by chemiluminescence with the aid of enhanced chemiluminescence detection kit for
HRP. $\beta$-actin was used to assess equal protein loading, and proteins levels were represented as protein level/ $\beta$-actin level.

\section{Statistical analysis}

All data are presented as mean \pm standard deviation (SD). One-way ANOVA was used to analyze differences among different groups with the aid of SPSS 21.0 (IBM SPSS Statistics, USA). Differences were considered statistically significant at $p<0.05$ or 0.01 .

\section{RESULTS}

\section{Effect of drug administration on rat body weight}

As shown in Figure 2, body weight of rats in all groups was gradually increased during the experimental period, and there were no significant differences among body weight of rats in different groups. These results suggested that body weight gain of rats was not affected significantly by drug administration, such as normal saline, alendronate, DEX and PDG.

\section{Effect of PDG on bone tissue parameters}

As shown in Table 1, the transverse diameter, weight, BMC and BMD of right femur in the control group were decreased significantly $(p<$ 0.01 ) relative to those in the normal group. After treatment with alendronate $(1 \mathrm{mg} / \mathrm{kg})$ or PDG $(10,20$, or $40 \mathrm{mg} / \mathrm{kg})$, the transverse diameter, weight, $\mathrm{BMC}$ and $\mathrm{BMD}$ of right femur in rats with OP were increased significantly $(p<0.05$ or $0.01)$, compared with those in the control group. Length of right femur was not affected significantly by drugs administration.

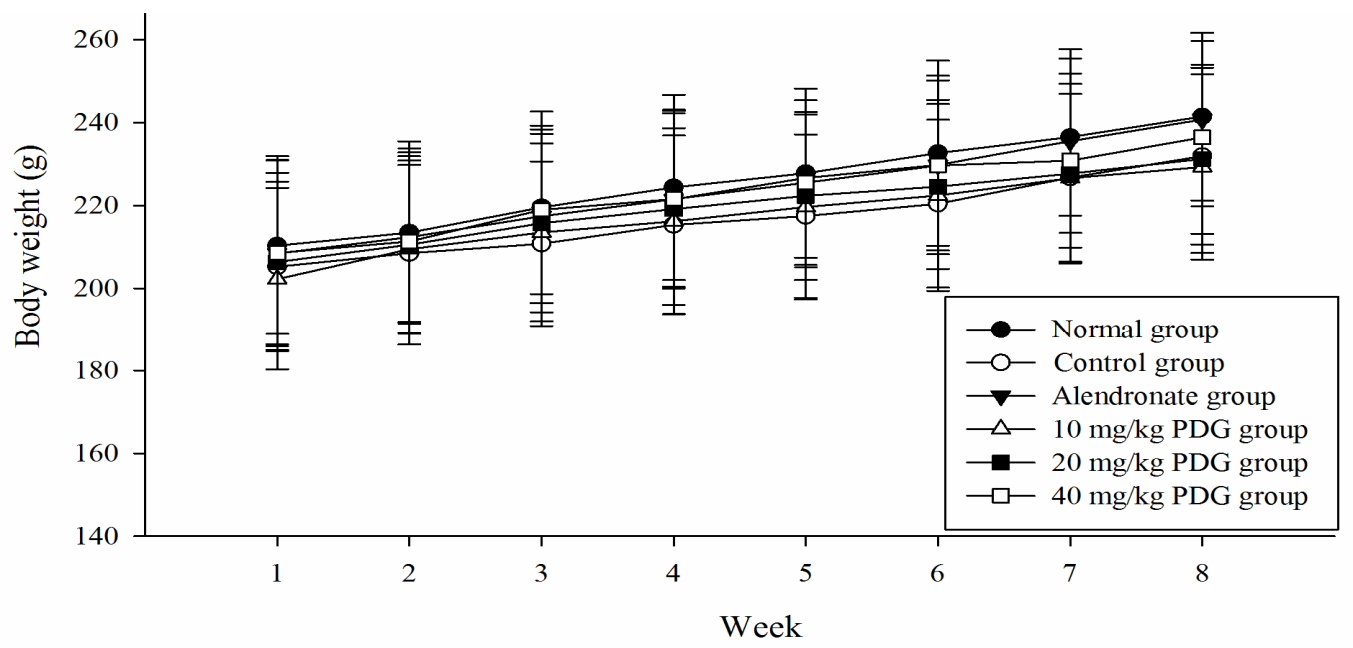

Figure 2: Effect of drug administration on rat body weight 
Table 1: Effect of PDG on length, transverse diameter, weight, BMC and BMD of right femur in rats with OP

\begin{tabular}{lccccc}
\hline Group & $\begin{array}{c}\text { Length } \\
(\mathbf{m m})\end{array}$ & $\begin{array}{c}\text { Transverse diameter } \\
(\mathbf{m m})\end{array}$ & $\begin{array}{c}\text { Weight } \\
(\mathbf{g})\end{array}$ & $\begin{array}{c}\text { BMC } \\
(\mathbf{g} / \mathbf{c m})\end{array}$ & $\begin{array}{c}\text { BMD } \\
\left(\mathbf{g} / \mathbf{c m}^{2}\right)\end{array}$ \\
\hline Normal & $32.81 \pm 1.98$ & $3.87 \pm 0.32$ & $0.81 \pm 0.10$ & $0.26 \pm 0.06$ & $0.36 \pm 0.05$ \\
control & $31.48 \pm 1.76$ & $3.31 \pm 0.26^{\# \#}$ & $0.67 \pm 0.05^{\# \#}$ & $0.12 \pm 0.03^{\# \#}$ & $0.22 \pm 0.03^{\# \#}$ \\
Alendronate & $32.57 \pm 1.62$ & $3.75 \pm 0.25^{\star *}$ & $0.76 \pm 0.06^{* *}$ & $0.24 \pm 0.05^{\star *}$ & $0.34 \pm 0.06^{* *}$ \\
$10 \mathrm{mg} / \mathrm{kg}$ PDG & $31.98 \pm 1.56$ & $3.64 \pm 0.19^{* *}$ & $0.73 \pm 0.07^{*}$ & $0.16 \pm 0.04^{*}$ & $0.27 \pm 0.04^{* *}$ \\
$20 \mathrm{mg} / \mathrm{kg}$ PDG & $32.72 \pm 1.74$ & $3.68 \pm 0.22^{* *}$ & $0.75 \pm 0.06^{* *}$ & $0.18 \pm 0.05^{* *}$ & $0.31 \pm 0.05^{* *}$ \\
$40 \mathrm{mg} / \mathrm{kg}$ PDG & $32.54 \pm 1.93$ & $3.79 \pm 0.23^{\star *}$ & $0.78 \pm 0.08^{* *}$ & $0.23 \pm 0.05^{* *}$ & $0.35 \pm 0.05^{* *}$ \\
\hline${ }^{\# \#} P<0.01$, compared with those in the normal group; ${ }^{*} p<0.05,{ }^{* *} p<0.01$, compared with those in the control \\
group
\end{tabular}

Table 2: Effect of PDG on serum $\mathrm{Ca}^{2+}$, IP, IL-6, TNF- $\alpha$ and ALP levels or activities in rats with OP

\begin{tabular}{|c|c|c|c|c|c|}
\hline Group & $\mathrm{Ca}^{2+}(\mathrm{mmol} / \mathrm{L})$ & IP (mmol/L) & ALP (U/L) & IL-6 (ng/L) & TNF- $\alpha$ (ng/L) \\
\hline Normal & $2.52 \pm 0.21$ & $1.12 \pm 0.14$ & $226.34 \pm 28.64$ & $92.63 \pm 3.64$ & $78.63 \pm 4.25$ \\
\hline Control & $1.94 \pm 0.18^{\# \#}$ & $1.76 \pm 0.22^{\# \#}$ & $486.45 \pm 35.67^{\# \#}$ & $108.74 \pm 5.98^{\# \#}$ & $92.38 \pm 5.69^{\# \#}$ \\
\hline Alendronate & $2.48 \pm 0.23^{* *}$ & $0.98 \pm 0.11^{* *}$ & $258.41 \pm 27.59^{\star *}$ & $93.47 \pm 3.14^{* *}$ & $80.16 \pm 3.85^{\star *}$ \\
\hline 10 mg/kg PDG & $2.16 \pm 0.15^{\star *}$ & $1.34 \pm 0.18^{* *}$ & $334.79 \pm 31.53^{* *}$ & $103.25 \pm 4.17^{*}$ & $87.46 \pm 4.13^{*}$ \\
\hline 20 mg/kg PDG & $2.27 \pm 0.19^{* *}$ & $1.21 \pm 0.16^{\star *}$ & $314.67 \pm 30.49^{* *}$ & $99.72 \pm 3.83^{* *}$ & $84.27 \pm 3.64^{* *}$ \\
\hline $40 \mathrm{mg} / \mathrm{kg}$ PDG & $2.39 \pm 0.22^{* *}$ & $1.14 \pm 0.17^{* *}$ & $276.32 \pm 29.86^{\star *}$ & $95.38 \pm 3.56^{* *}$ & $82.05 \pm 3.71^{\text {** }}$ \\
\hline
\end{tabular}

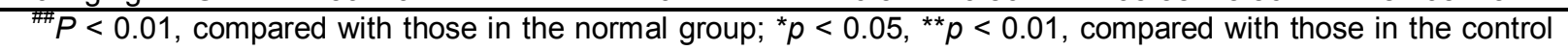
group

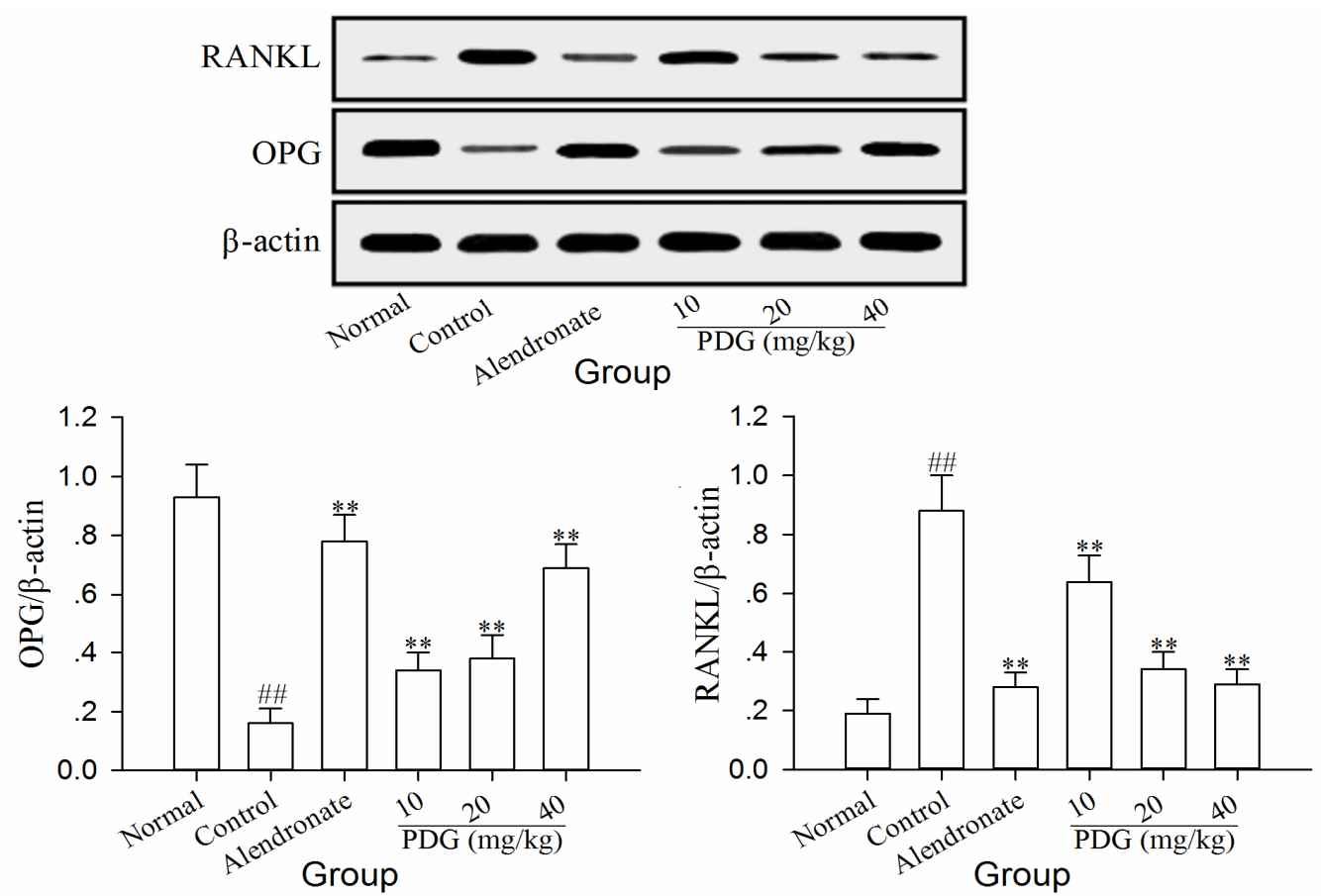

Figure 3: Effect of PDG on OPG and RANKL levels of left femur in rats with OP; ${ }^{\# \#} p<0.01$, compared with those in the normal group; ${ }^{* *} p<0.01$, compared with those in the control group

\section{Effect of PDG on serum biochemical indices}

As listed in Table 2, serum $\mathrm{Ca}^{2+}$ level in the control group was decreased significantly $(p<$ 0.01 ) and serum IP, IL-6, TNF- $\alpha$ and ALP levels or activities in the control group were increased significantly $(p<0.01)$, compared with those in the normal group. After treatment with alendronate $(1 \mathrm{mg} / \mathrm{kg})$ or PDG $(10,20$ or 40 $\mathrm{mg} / \mathrm{kg}$ ), serum $\mathrm{Ca}^{2+}$ level in rats with OP was increased significantly $(p<0.01)$ and serum IP, IL-6, TNF- $\alpha$ and ALP levels or activities in rats with OP were decreased significantly $(p<0.05$ or $0.01)$, compared with those in the control group.

\section{Effect of PDG on OPG and RANKL levels of left femur in rats with OP}

As shown in Figure 3, the OPG level of left femur in the control group was decreased significantly 
$(p<0.01)$ and the RANKL level of left femur in the control group was increased significantly $(p<$ 0.01 ), compared with those in the normal group. After treatment with alendronate $(1 \mathrm{mg} / \mathrm{kg})$ or PDG $(10,20$, or $40 \mathrm{mg} / \mathrm{kg}$ ), the OPG level of left femur in rats with OP was increased significantly $(p<0.01)$ and the RANKL level of left femur in rats with OP was decreased significantly $(p<$ $0.01)$, compared with those in the control group.

\section{DISCUSSION}

In this work, the protective effects and possible mechanisms of PDG against DEX-induced OP in rats were investigated for the first time. Body weight is a critical and direct index to evaluate the effect of drugs on body functions, such as gastrointestinal functions and physiological metabolism [12]. In the study, the body weight gain of rats was not affected by drugs administration, suggesting that the results of this study were credible and not affected by the notable side effect caused by the drugs administration.

$B M C$ and BMD are two meaningful indices to assess bone quality and are closely related to degree of OP $[13,14]$. Length, transverse diameter and weight of right femur can directly reflect quality of bone [15]. In the study, the transverse diameter, weight, BMC and BMD of right femur in the control group were decreased relative to those in the normal group, and these reductions were reversed by alendronate a known drug used to treat OP [16], indicating that the OP model and known treatment were successfully established and administrated. Meanwhile, these reductions were also reversed by PDG $(10,20$ or $40 \mathrm{mg} / \mathrm{kg})$, suggesting that PDG showed protective effect on DEX-induced $\mathrm{OP}$ by increasing bone mass.

ALP, a phosphomonoesterase, is secreted from osteoblast and is widely distributed in various kinds of tissues and organs, especially bone and liver [17]. ALP activity can reflect differentiated degree of osteoblast, used to evaluate bone formation ability [18]. Bone consists of bone mineral and matrix, and calcium and phosphorus are the maximum mineral composition in bone matrix. When blood calcium level is low, calcium in bone matrix can be released into blood to keep normal blood calcium level [19]. Glucocorticoids can cause the reduction of blood calcium level by inhibiting transmembrane transport and intestinal absorption of calcium and increasing excretion of calcium [20]. Negative calcium balance can compensatorily increase blood phosphorus level by promoting the release of phosphorus in bone matrix into blood and can further promote the release of calcium in bone matrix into blood [21]. These glucocorticoids-induced changes can increase bone resorption, which compensatorily increase ALP activity to promote bone formation [22]. The glucocorticoids-induced bone resorption and abnormal bone reconstruction lead to the occurrence of OP. In the study, the DEX-induced reduction of serum $\mathrm{Ca}^{2+}$ level and increase of serum IP level and ALP activity were reversed by PDG $(10,20$ or $40 \mathrm{mg} / \mathrm{kg})$, suggesting that PDG showed protective effect on DEX-induced OP by regulating bone metabolism. IL-6 and TNF- $\alpha$ can increase bone resorption and inhibit bone formation by inducing the differentiation of osteoclast precursor cell to osteoclast, promoting degradation of bone matrix and inhibiting activity of osteoblast [23]. The results of this study indicated that the DEXinduced increase of serum IL- 6 and TNF- $\alpha$ level were reversed by PDG $(10,20$ or $40 \mathrm{mg} / \mathrm{kg})$, indicating that PDG showed protective effect on DEX-induced OP by regulating bone metabolism. OPG/RANKL/RANK system plays an interactive role in generation of osteoclast and the balance between bone resorption and bone formation [24]. Combination between RANKL and RNAK with tumor necrosis factor receptor related factors can promote bone resorption by inducing differentiation of osteoclast precursor cell to osteoclast. OPG can inhibit the differentiation of osteoclast precursor cell to osteoclast by competitively inhibiting the combination between RANKL and RNAK [25]. In the study, the DEXinduced reduction of OPG protein level in left femur and increase of RANKL protein level in left femur were reversed by PDG $(10,20$ or 40 $\mathrm{mg} / \mathrm{kg}$ ), indicating that PDG showed protective effect on DEX-induced the unbalance between bone resorption and bone formation.

\section{CONCLUSION}

PDG exhibits a protective effect on DEX-induced $\mathrm{OP}$ in rats by increasing bone mass and regulating bone metabolism, which is achieved by regulating serum $\mathrm{Ca}^{2+}$, IP, IL-6, TNF- $\alpha$ and ALP levels or activities as well as OPG and RANKL protein levels in bone tissue. Thus, PDG has a potential to be a candidate drug for treating OP. This, however, needs to be further investigated to ascertain the effect of PDG on OP in humans.

\section{DECLARATIONS}

\section{Acknowledgement}

The authors would like to acknowledge support from their colleagues in Department of 
Orthopaedics, The First People's Hospital of Huzhou.

\section{Conflict of Interest}

No conflict of interest associated with this work.

\section{Contribution of Authors}

The authors declare that this work was done by the authors named in this article and all liabilities pertaining to claims relating to the content of this article will be borne by them.

\section{Open Access}

This is an Open Access article distributed under the terms of the Creative Commons Attribution License, which permits unrestricted use, distribution, and reproduction in any medium, provided the original work is properly credited.

\section{REFERENCES}

1. Svedbom A, Ivergård $M$, Hernlund E, Rizzoli R, Kanis JA. Epidemiology and economic burden of osteoporosis in Switzerland. Arch Osteoporos 2014; 9: 187.

2. Elayeh E, Akour A, Yousef A, Farah D, Hamaly $M$, Basheti I. Osteoporosis amongst Jordanians: effect of pharmacist-directed brochure education on people's knowledge. Trop J Pharm Res 2014; 13(12): 2101-2108.

3. von Scheven E, Corbin KJ, Stagi S, Cimaz $R$. Glucocorticoid-associated osteoporosis in chronic inflammatory diseases: epidemiology, mechanisms, diagnosis, and treatment. Curr Osteoporos Rep 2014; 12(3): 289-299.

4. Jacobs J, Korswagen $L A$, Schilder $A M$, van Tuyl $L H$, Dijkmans BA, Lems WF, Voskuyl AE, Bultink IE. Sixyear follow-up study of bone mineral density in patients with systemic lupus erythematosus. Osteoporos Int 2013; 24(6): 1827-1833.

5. Ziegler TE, Sosa ME, Peterson LJ, Colman RJ. Using snacks high in fat and protein to improve glucoregulatory function in adolescent male marmosets (Callithrix jacchus). J AM Assoc Lab Anim Sci 2013; 52(6): 756-762.

6. Munck A, Guyre PM, Holbrook NJ. Physiological functions of glucocorticoids in stress and their relation to pharmacological actions. Endocr Rev 1984; 5(1): 25-44.

7. Buehring $B$, Viswanathan $R$, Binkley $N$, Busse $W$. Glucocorticoid-induced osteoporosis: an update on effects and management. J Allergy Clin Immunol 2013; 132(5):1019-1030.

8. Pan Y, Niu Y, Li C, Zhai Y, Zhang R, Guo X, Mei Q. DuZhong (Eucommia ulmoides) prevents disuse-induced osteoporosis in hind limb suspension rats. Am J Chin Med 2014; 42(1): 143-155.
9. Zhang R, Liu ZG, Li C, Hu SJ, Liu L, Wang JP, Mei QB. Du-Zhong (Eucommia ulmoides Oliv.) cortex extract prevent OVX-induced osteoporosis in rats. Bone 2009; 45(3): 553-559.

10. Lin F, Wang YH, Wan L, Yang RP. Study on the quality control of Eucommiae cortex by multi-components quantitation by one marker method and fingerprint. Chin J Exper Trad Med Formu 2012; 18(12): 78-82.

11. The National Research Council of The National Academy of Sciences. Guide for the Care and Use of Laboratory Animals: Eight Edition. Washington, D.C.: The National Academies Press; 2010.

12. Lin $\mathrm{CH}$, Chen CC, Wong J, Mclntyre RS. Both body weight and $\mathrm{BMI}$ predicts improvement in symptom and functioning for patients with major depressive disorder. $J$ Affect Disord 2014; 161: 123-126.

13. Aspray TJ, Prentice A, Cole TJ, Sawo Y, Reeve J, Francis RM. Low bone mineral content is common but osteoporotic fractures are rare in elderly rural Gambian women. J Bone Miner Res 1996; 11(7): 1019-1025.

14. Sun $T$, Chen $M$, Lin $X, Y u R$, Zhao $Y$, Wang J. The influence of osteoprotegerin genetic polymorphisms on bone mineral density and osteoporosis in Chinese postmenopausal women. Int Immunopharmacol 2014; 22(1): 200-203.

15. Khaleel N, Hussain SS. Osteometric study of human femur. Int J Res Med Sci 2014; 2(1): 104-107.

16. Iwamoto J, Miyata A, Sato Y, Takeda T, Matsumoto $H$. Factors affecting discontinuation of alendronate treatment in postmenopausal Japanese women with osteoporosis. J Clin Med Assoc 2009; 72(12): 619-624.

17. Buchet R, Millán JL, Magne D. Multisystemic functions of alkaline phosphatases. Methods Mol Biol 2013; 1053: 27-51.

18. Modareszadeh MR, Di Fiore PM, Tipton DA, Salamat $N$. Cytotoxicity and alkaline phosphatase activity evaluation of endosequence root repair material. J Endod 2012; 38(8): 1101-1105.

19. Boonrungsiman S, Gentleman E, Carzaniga R, Evans $N D$, McComb DW, Porter AE, Stevens MM. The role of intracellular calcium phosphate in osteoblast-mediated bone apatite formation. Proc Natl Acad Sci USA 2012; 109(35): 14170-14175.

20. Seibel MJ, Cooper MS, Zhou H. Glucocorticoid-induced osteoporosis: mechanisms, management, and future perspectives. Lancet Diabetes Endocrinol 2013; 1(1): 59-70.

21. Lieben L, Carmeliet G. The delicate balance between vitamin $D$, calcium and bone homeostasis: lessons learned from intestinal-and osteocyte-specific VDR null mice. J Sterodi Biochem Mol Biol 2013; 136: 102-106.

22. Ko JY, Chuang PC, Chen MW, Ke HC, Wu SL, Chang YH, Chen YS, Wang FS. MicroRNA-29a ameliorates glucocorticoid-induced suppression of osteoblast differentiation by regulating $\beta$-catenin acetylation. Bone 2013; 57(2): 468-475.

23. Kwan Tat S, Padrines M, Théoleyre S, Heymann D, Fortun Y. IL-6, RANKL, TNF-alpha/IL-1: interrelations in

Trop J Pharm Res, November 2016; 15(11): 2456 
Zhang et al

bone resorption pathophysiology. Cytokine Growth Factor Rev 2004; 15(1): 49-60.

24. Walsh WC, Choi Y. Biology of the RANKL-RANK-OPG system in immunity, bone, and beyond. Front Immunol 2014; 5: 511.
25. Aoki K, Saito $H$, Itzstein $C$, Ishiguro $M$, Shibata $T$, Blanque R, Mian AH, Takahashi M, Suzuki $Y$, Yoshimatsu M, et al. A TNF receptor loop peptide mimic blocks RANK ligand-induced signaling, bone resorption, and bone loss. J Clin Invest 2006; 116(6): 1525-1534. 